\title{
Autologous chondrocyte implantation (ACl) for the treatment of large and complex cartilage lesions of the knee
}

\author{
Christian Ossendorf ${ }^{1 *}$, Matthias R Steinwachs², Peter C Kreuz ${ }^{3}$, Georg Osterhoff ${ }^{1}$, Andreas Lahm ${ }^{4}$, \\ Pascal P Ducommun ${ }^{5}$ and Christoph Erggelet ${ }^{6}$
}

\begin{abstract}
Background: Complex cartilage lesions of the knee including large cartilage defects, kissing lesions, and osteoarthritis $(\mathrm{OA})$ represent a common problem in orthopaedic surgery and a challenging task for the orthopaedic surgeon. As there is only limited data, we performed a prospective clinical study to investigate the benefit of autologous chondrocyte implantation (ACl) for this demanding patient population.

Methods: Fifty-one patients displaying at least one of the criteria were included in the present retrospective study: (1.) defect size larger than $10 \mathrm{~cm}^{2}$; (2.) multiple lesions; (3.) kissing lesions, cartilage lesions Outerbridge grade III-IV, and/or (4.) mild/moderate osteoarthritis (OA). For outcome measurements, the International Cartilage Society's International Knee Documentation Committee's (IKDC) questionnaire, as well as the Cincinnati, Tegner, Lysholm and Noyes scores were used. Radiographic evaluation for OA was done using the Kellgren score.

Results and Discussion: Patient's age was 36 years (13-61), defects size $7.25(3-17.5) \mathrm{cm}^{2}$, previous surgical procedures 1.94 (0-8), and follow-up 30 (12-63) months. Instruments for outcome measurement indicated significant improvement in activity, working ability, and sports. Mean ICRS grade improved from 3.8 preoperatively to grade 3 postoperatively, Tegner grade 1.4 enhanced to grade 3.39. The Cincinnati score enhanced from 25.65 to 66.33, the Lysholm score from 33.26 to 64.68, the Larson score from 43.59 to 79.31 , and Noyes score from 12.5 to 46.67, representing an improvement from Cincinnati grade 3.65 to grade 2.1. Lysholm grade 4 improved to grade 3.33, and Larson grade 3.96 to 2.78 (Table 1), ( $p<0.001$ ). Patients with kissing cartilage lesions had similar results as patients with single cartilage lesions.
\end{abstract}

Conclusion: Our results suggest that $\mathrm{ACl}$ provides mid-term results in patients with complex cartilage lesions of the knee. If long term results will confirm our findings, ACl may be a considered as a valuable tool for the treatment of complex cartilage lesions of the knee.

\section{Introduction}

Autologous chondrocyte implantation (ACI) has been recommended for the treatment of symptomatic cartilage defects of approximately $2.5-10 \mathrm{~cm}^{2}$. Smaller defects are usually treated by microfracture resulting in fibrocartilaginous repair tissue with only limited durability [1-4], while ACI provides hyaline like cartilage [4]. Large cartilage defects, kissing lesions and OA cannot

\footnotetext{
* Correspondence: christian.ossendorf@usz.ch

'Department of Surgery, Division of Trauma Surgery, University Hospital

Zurich, Raemistrasse 100, 8091 Zurich, Switzerland

Full list of author information is available at the end of the article
}

be addressed by microfracture. In addition, cartilage defects are frequently accompanied by anterior cruciate ligament (ACL) tears, meniscus injuries, or malalignment. Hence, these defects represent a challenging task for the orthopaedic surgeon, as -particularly in younger patients- surgical treatment options providing proper knee joint function at follow-up are usually limited. Arthroscopic debridement was shown to be insufficient for the treatment of mild and moderate OA. Total knee arthroplasty (THA) provides good results in elderly. However, in younger patients, the outcome of THA is less favorable. Moreover, due to the young age of
C Biomed Central

() 2011 Ossendorf et al; licensee BioMed Central Ltd. This is an Open Access article distributed under the terms of the Creative Commons Attribution License (http://creativecommons.org/licenses/by/2.0), which permits unrestricted use, distribution, and reproduction in any medium, provided the original work is properly cited. 
Table 1 Mean scores and grades at surgery (Tx) and at follow-up

\begin{tabular}{lllll}
\hline & Tx & & Follow-up \\
& Score & Grade & Score & Grade \\
\hline ICRS & & 4 & & 3 \\
Tegner & & 1 & & 3 \\
Noyes & 13 & & 47 & \\
Cincinnati & 26 & 4 & 66 & 2 \\
Lysholm & 33 & 4 & 65 & 3 \\
Larson & 44 & 4 & 79 & 3 \\
\hline
\end{tabular}

patients, revision surgery will be unavoidable after several years. Patients with the profile described above, usually physically active, frequently present with sometimes yearlong and often immobilizing pain. Often, they have a history of cartilage debridement and microfracture and/or various knee surgeries before presentation at our department. Sporadically, we performed ACI in patients with complex and large cartilage lesions of the knee. Follow-up examinations revealed encouraging results. Therefore, we were prompted to assess ACI in this challenging group of patients.

\section{Materials and methods}

Fifty-one patients (18 female, 33 male; age 36 (13-61) years; 78 cartilage defects) with at least one of the following criteria were included in the present retrospective study: cartilage defect larger $10 \mathrm{~cm}^{2}$, multiple lesions, kissing lesions, and OA, respectively. All but 5 defects were classified as Outerbridge [5] Grade IV, mainly on the medial femoral condyle $(\mathrm{n}=35)$, whereas 10 lesions were on the lateral femoral condyle, and 15 on patella and trochlea, respectively (Figure 1, Table 2). Mean defects size was $7.25(3-17.5) \mathrm{cm}^{2}$. Average follow-up was 30 months (12-63). In 33 cases, the defects were situated on the right knee, in 18 cases on the left. Fourteen patients showed traumatic defects; 22 degenerative defects, and 15 patients had osteochondritis dissecans (OD) lesions. Number of previous surgeries was $1.94(0-8)$. In addition to ACI, concomitant surgical procedures as anterior cruciate ligament (ACL) reconstruction $(\mathrm{n}=1)$, patella realignment surgery $(\mathrm{n}=1)$, high tibial osteotomy (HTO), $(n=8)$, microfracture $(n=3)$, and osteochondral autograft transfer (OATS), $(n=11)$ were done in 23 patients (Table 2). Patients were divided into 3 groups: single lesions $(n=23)$, complex lesions $(n=19)$, and kissing lesions $(n=9)$.

Preoperative leg axis was determined in every case. Malalignment was corrected in the same session with ACI. In 1 patient with ACL-lesion, ACL-repair was done prior to ACI in the same operation using a graft. One patient had an Ali Crogius procedure due to femoro-patellar instability. None of the patients had concomitant meniscus surgery. No patient with severe varus/valgus deformity was excluded from the present

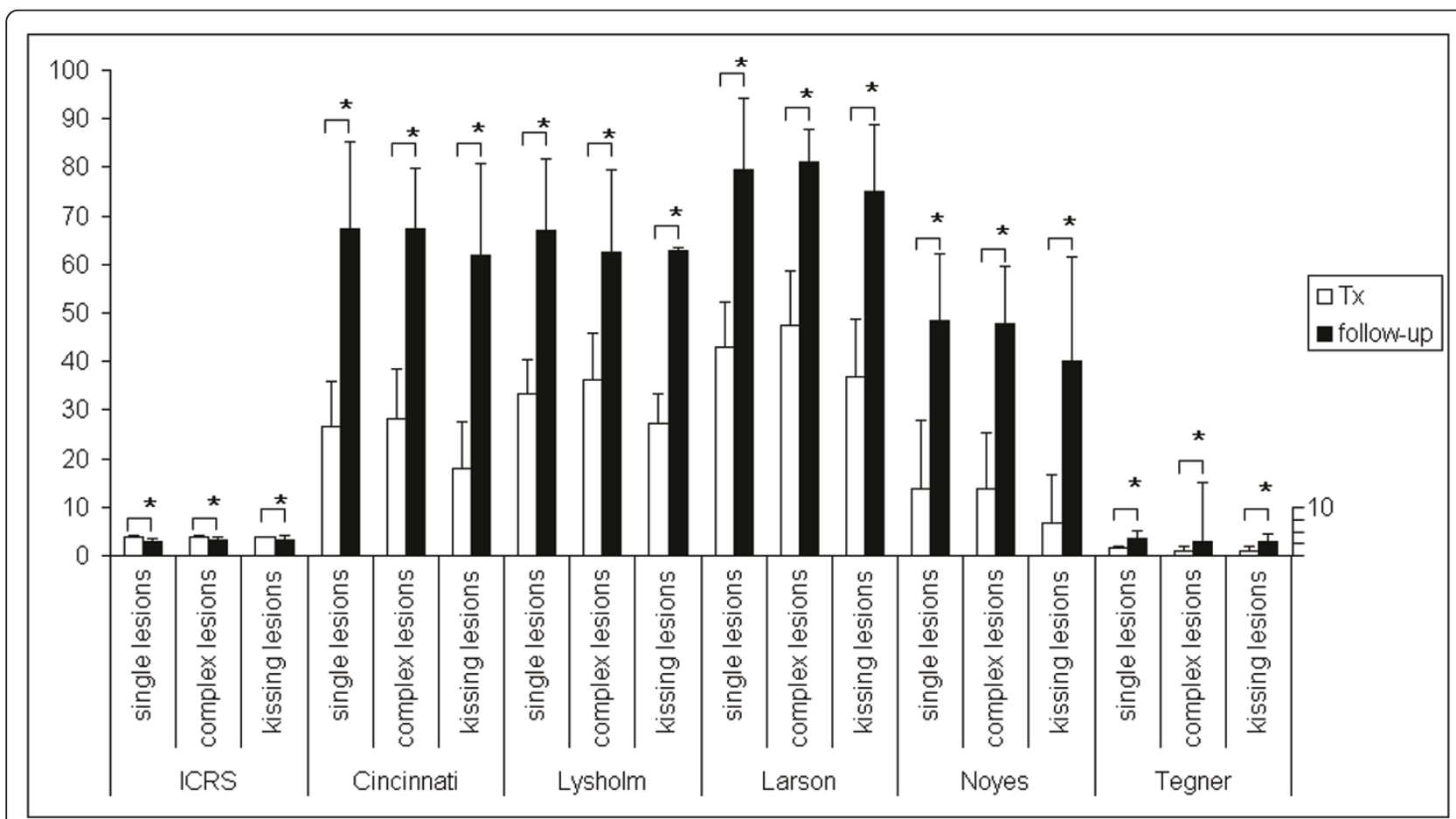

Figure 1 Patients were divided into 3 groups: single lesions $(n=23)$, complex lesions $(n=19)$, and kissing lesions $(n=9)$ at surgery (Tx) and at follow-up. Values are reported as mean+/-standard deviation with * indicating statistically relevant changes. 
Table 2 Patient's characteristics

\begin{tabular}{ll}
\hline Characteristic & \\
\hline Gender & 33 male, 18 female \\
Age (years) & 36 (range 13-61) \\
Height $(\mathrm{cm})$ & 176 (range 140-196) \\
Weight $(\mathrm{kg})$ & 74 (range 45-98) \\
Treated knee & 33 right, 18 left \\
Defect size ( $\left.\mathrm{cm}^{2}\right)$ & 7.2 (3-17.5) \\
Cartilage grade & 1 grade III, 50 grade IV (1st lesion); 4 grade \\
& III, 23 grade IV (2nd lesion) \\
Localization (1st lesion) & 32 medial, 7 lateral, 5 patella, 7 intercondylar \\
& notch \\
Etiology & 14 traumatic, 22 degenerative, 15 OD \\
Number of previous & $7 \times 0,18 \times 1,11 \times 3,4 \times 4,1 \times 5,1 \times 7,1$ \\
surgical procedures & $\times 8$ \\
Additional procedures & 1 ACL-reconstructions, 1 Ali Crogius, 8 HTO, \\
& 3 microfractures, 11 OATS \\
Previous surgical & 20 meniscectomies, 5 ACL-reconstructions, 5 \\
procedures & lateral releases, 14 drilling/microfracture, 7 \\
& abrasion arthroplasty \\
\hline
\end{tabular}

study. For evaluation of treatment outcome, ICRS [6], Cincinnati [7-9], Tegner [9], Lysholm [10], Larson [11] and the Noyes [7] scores were used. For radiographic evaluation, the Kellgren radiographic score was applied $[12,13]$. The present study was approved by the local ethical commission. All patients gave their informed consent to participate in the study. All patients were examinated by an investigator independent from the surgical and outpatient teams, respectively. Statistical analysis was performed using the paired Wilcoxon-rank sum test with SPSS for Windows 11.5 (SPSS, Chicago, U.S.A.). The level of significance was set to $5 \%$.

\section{Surgical technique}

For ACI, the cartilage defect was assessed arthroscopically for definite indication to ACI. Approximately 250 $\mathrm{mg}$ of articular cartilage was taken as a biopsy from a lesser or non weight bearing region of the knee as the linea terminalis or the intercondylar notch. The biopsy was placed in transport container provided by the commercial cell culturing company and sent to the company's cell culturing facility (Genzyme Biosurgery, Cambridge, MA, U.S.A.). There, chondrocytes were expanded in vitro and brought into a suspension for later injection. Approximately three to six weeks later the implantation of the cultured autologous chondrocytes was performed. Under general anesthesia and antibiotic prophylaxis, a standard arthrotomy was performed preparing the cartilage defect in a tourniquet-controlled bloodless field. The cartilage lesion was carefully debrided back to healthy cartilage building a stable rim. A template was fitted to defect size and periosteum was harvested from the lateral aspect of the tibia using this template. This periosteal flap was fitted to defect size and sutured into the defect cambium layer down (Vicryl 6-0), leaving a gap for the injection of the cultured chondrocytes. The rim was sealed with fibrin glue. The chondrocyte suspension was injected under the periosteal flap and the flap was finally secured and sealed with fibrin glue and a final suture.

\section{Results}

No patient was lost to follow-up. Postoperatively, no knee joint infection occurred. Two patients showed an extension deficit of $5^{\circ}$. No flexion deficiency could be observed at latest follow-up. All patients were able to bend and flex the knee operated on to at least $120^{\circ}$ Overall, mean ICRS grade improved from 3.8 preoperatively to grade 3 postoperatively, Tegner grade 1.4 enhanced to grade 3.39. The Cincinnati score enhanced from 25.65 to 66.33 , the Lysholm score from 33.26 to 64.68 , the Larson score from 43.59 to 79.31 , and Noyes score from 12.5 to 46.67, representing an improvement from Cincinnati grade 3.65 to grade 2.1. Lysholm grade 4 improved to grade 3.33, and Larson grade 3.96 to 2.78 (Table 1). All score improvements were statistically relevant $(\mathrm{p}<0.001)$.

Average grade of OA was 1.28. No signs of OA could be determined on plain radiographs in 17 patients, initial OA was present in 5, mild in 25 and moderate in 3 patients.

Results in patients with complex defects and such displaying kissing lesions were not worse than patients with single lesions (Figure 2). Evaluated by using the ICRS and Tegner score, patients of all 3 groups showed a high level of resemblance (Figure 2). Noyes and Cincinnati scores showed nearly similar patterns of improvement for single, complex and kissing lesions. Within the respective groups, scoring results of single lesions resembled those of complex lesions, both, preoperatively and at follow-up. Patients with kissing lesions scored better than those of the other groups when using the Lysholm and Larson score, while patients with complex lesions scored worse (Figure 2), although the differences were not statistically relevant.

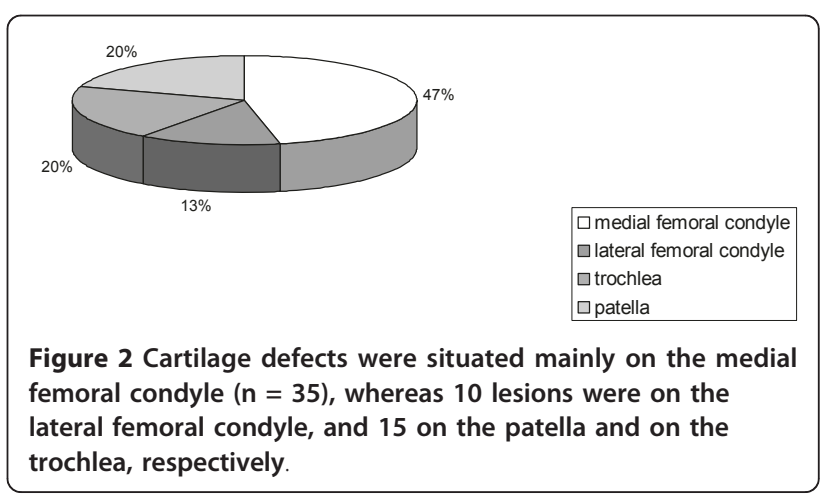


During the follow-up period, 27 patients required reoperations mostly due to persistent symptoms like locking or catching sensations, pain or swelling. The outcome of these reoperations comprised shavings/debridements $(n=23)$, synovectomies $(n=5)$, microfracture $(\mathrm{n}=4)$, meniscectomies $(\mathrm{n}=3)$, autologous chondrocyte implantation as revision procedure $(\mathrm{n}=3)$, and patella realignment surgery $(n=1)$, (Table 3$)$. Reoperations were recorded regardless whether the adverse event was related to ACI. Two patients required total knee arthroplasty (THA) later on.

\section{Discussion}

The aim of the present study was to evaluate ACI in patients with complex and large cartilage lesions of the knee such as large defects, multiple lesions, kissing lesions or OA. Highly significant improvements in activity level and in sports were observed. A relatively high number of patients required revision surgery due to locking or catching sensations. Potential weaknesses of the present study emerge from the context of heterogeneous patient population including patient's age and number of previous surgical procedures. No biopsies were available for analysis of replacement tissue quality.

Evolution of ACI technology with matrix-induced ACI (MACI) potentially comprises less morbidity, as no periosteum has to be harvested [14]. In contrast, periosteum alone was shown to be capable to promote cartilage formation $[15,16]$. Therefore, the proportion of either the periosteal graft or the chondrocyte suspension to formation of the repair tissue remains to be clarified. Some authors recommend $\mathrm{ACI}$ as a salvage procedure or treatment option in the arthritic knee [17]. Here, significant improvements in quality of life, pain relief, and in activity in patients with multiple lesions alone were shown. Patients with high tibial valgus osteotomy and such with patellofemoral defects were doing worse. In the present study we could not confirm these findings, as no significant differences in our patients with the named conditions could be observed. This might be caused by the smaller number of patients in our study and the consecutive statistic effects. Other authors considered $\mathrm{ACI}$ as unsuitable for $\mathrm{OA}$ [2]. In contrast, recent

Table 3 Reoperations in 27 patients

\begin{tabular}{lc}
\hline Procedure & \\
\hline Shaving & 23 \\
Synovectomy & 5 \\
Microfracture & 4 \\
Meniscectomy & 3 \\
ACl & 3 \\
Ali Crogius & 1 \\
\hline
\end{tabular}

studies successfully used ACI in the treatment of early stage and/or early OA $[4,18]$.

In the evaluation of cartilage repair procedures there are basically two methods: biopsy and the use of scoring systems, each of which has specific advantages and disadvantages. Though a biopsy provides a clear picture of the type and quality of repair tissue, it is difficult to gather specimens from asymptomatic and well-being patients.

One score alone does not cover all the desired facts, so that at least two or more scores have to be used. We may speculate that our encouraging mid-term results will represent decent long-term outcome also in the future. Nevertheless, status at two years follow-up seems to be of particular importance for long-term prognosis [19].

The treatment of complex cartilage lesions, especially in younger patients having expectations in his or her ability to work and quality of live represents a challenging task for the orthopaedic surgeon.

In conclusion, our results suggest that $\mathrm{ACI}$ is a capable of improving mid-term results in patients with complex cartilage lesions of the knee. If long term results will confirm our findings, ACI may be a valuable tool not only for focal defects but also for the treatment of complex cartilage lesions of the knee. ACI may also be used to delay the need for total knee arthroplasty.

\section{Acknowledgements}

Investigation performed at the Department of Orthopaedics and Trauma Surgery, University of Freiburg, Germany

\section{Author details}

${ }^{1}$ Department of Surgery, Division of Trauma Surgery, University Hospital Zurich, Raemistrasse 100, 8091 Zurich, Switzerland. 'Division of Orthobiology and Cartilage Repair, Schulthess Clinic, Lengghalde 2, 8008 Zurich,

Switzerland. ${ }^{3}$ Department of Orthopaedics, University of Rostock, Doberaner Strasse 142, 18057 Rostock, Germany. ${ }^{4}$ Department of Orthopaedics, University of Greifswald, F.-v.-Sauerbruchstr., 17475 Greifswald, Germany. ${ }^{5}$ Department of Surgery, Division of Plastic, Aesthetic and Hand Surgery, University Hospital Zurich, Raemistrasse 100, 8091 Zurich, Switzerland. ${ }^{6}$ Department of Orthopaedics and Trauma Surgery, University of Freiburg, Hugstetter Str. 55, 79106 Freiburg, Germany.

\section{Authors' contributions}

CO conceived and performed the study and drafted the manuscript. MRS participated in the design of the study, evaluation of the data and writing the manuscript. PCK, GO, AL and PPD participated in evaluation of data, drafting of the manuscript, and statistical analysis of the study. CE conceived the study, participated in its design, evaluation of data and in drafting of the manuscript. All authors read and approved the final version of the manuscript.

\section{Competing interests}

The authors declare that they have no competing interests.

Received: 1 September 2010 Accepted: 21 May 2011

Published: 21 May 2011

References

1. Bentley G, Biant LC, Carrington RW, Akmal M, Goldberg A, Williams AM, Skinner JA, Pringle J: A prospective, randomised comparison of 
autologous chondrocyte implantation versus mosaicplasty for osteochondral defects in the knee. J Bone Joint Surg Br 2003, 85-2:223-30.

2. Nehrer S, Dorotka R, Domayer S, Stelzeneder D, Kotz R: Treatment of fullthickness chondral defects with hyalograft $C$ in the knee: a prospective clinical case series with 2 to 7 years' follow-up. Am J Sports Med 2009, 37(Suppl 1):81S-7S.

3. Lee KB, Bai LB, Yoon TR, Jung ST, Seon JK: Second-look arthroscopic findings and clinical outcomes after microfracture for osteochondral lesions of the talus. Am J Sports Med 2009, 37(Suppl 1):63S-70S.

4. Minas T, Gomoll AH, Solhpour S, Rosenberger R, Probst C, Bryant T: Autologous chondrocyte implantation for joint preservation in patients with early osteoarthritis. Clin Orthop Relat Res 2010, 468-1:147-57.

5. Outerbridge RE: The etiology of chondromalacia patellae. J Bone Joint Surg Br 1961, 43-B:752-7.

6. Internaional Cartilage Repair Society (ICRS). [http://www.cartilage.org].

7. Noyes FR, Barber SD, Mooar LA: A rationale for assessing sports activity levels and limitations in knee disorders. Clin Orthop Relat Res 1989, 246:238-49.

8. Noyes FR, Barber-Westin SD: Arthroscopic-assisted allograft anterior cruciate ligament reconstruction in patients with symptomatic arthrosis. Arthroscopy 1997, 13-1:24-32.

9. Tegner $Y$, Lysholm J: Rating systems in the evaluation of knee ligament injuries. Clin Orthop Relat Res 1985, 198:43-9.

10. Lysholm J, Gillquist J: Evaluation of knee ligament surgery results with special emphasis on use of a scoring scale. Am J Sports Med 1982, 103:150-4.

11. Larson CB: Rating scale for hip disabilities. Clin Orthop Relat Res 1963, 31:85-93.

12. Kellgren JH, Lawrence JS: Radiological assessment of osteo-arthrosis. Ann Rheum Dis 1957, 16-4:494-502.

13. Kellgren JH, Lawrence JS: Radiological assessment of rheumatoid arthritis. Ann Rheum Dis 1957, 16-4:485-93.

14. Behrens P, Bitter T, Kurz B, Russlies M: Matrix-associated autologous chondrocyte transplantation/implantation (MACT/MACl)-5-year followup. Knee 2006, 13-3:194-202.

15. O'Driscoll SW: Articular cartilage regeneration using periosteum. Clin Orthop Relat Res 1999, 367(Suppl):S186-203.

16. O'Driscoll SW, Meisami B, Miura Y, Fitzsimmons JS: Viability of periosteal tissue obtained postmortem. Cell Transplant 1999, 8-6:611-6.

17. Ossendorf C, Kaps C, Kreuz PC, Burmester GR, Sittinger M, Erggelet C: Treatment of posttraumatic and focal osteoarthritic cartilage defects of the knee with autologous polymer-based three-dimensional chondrocyte grafts: 2-year clinical results. Arthritis Res Ther 2007, 9-2:R41.

18. Niemeyer P, Lenz P, Kreuz PC, Salzmann GM, Sudkamp NP, Schmal H, Steinwachs M: Chondrocyte-seeded type I/III collagen membrane for autologous chondrocyte transplantation: prospective 2-year results in patients with cartilage defects of the knee joint. Arthroscopy 2010, 268:1074-82

19. Petersen JP, Ueblacker P, Goepfert C, Adamietz P, Baumbach K, Stork A, Rueger JM, Poertner R, Amling M, Meenen NM: Long term results after implantation of tissue engineered cartilage for the treatment of osteochondral lesions in a minipig model. J Mater Sci Mater Med 2008 19-5:2029-38.

doi:10.1186/1758-2555-3-11

Cite this article as: Ossendorf et al: Autologous chondrocyte implantation (ACl) for the treatment of large and complex cartilage lesions of the knee. Sports Medicine, Arthroscopy, Rehabilitation, Therapy \& Technology 2011 3:11.

\section{Submit your next manuscript to BioMed Central and take full advantage of:}

- Convenient online submission

- Thorough peer review

- No space constraints or color figure charges

- Immediate publication on acceptance

- Inclusion in PubMed, CAS, Scopus and Google Scholar

- Research which is freely available for redistribution

Submit your manuscript at www.biomedcentral.com/submit
Ciomed Central 